\title{
Self-reported Attributes Associated with Cognition and Motivation as a Function of Gender
}

Trevor Archer ${ }^{1 *}$, Ann-Christine Arntén ${ }^{1}$, Klaus Olsen ${ }^{2}$ and Bengt Jansson ${ }^{1,2}$

${ }^{1}$ Department of Psychology, University of Gothenburg, Gothenburg, Sweden

${ }^{2}$ Job Match Talent, Job Match Sweden AB, University of Gothenburg, Gothenburg, Sweden

\begin{abstract}
Male $(n=4141)$ and Female $(n=2648)$ participants in executive leadership recruitment self-report were compared with regard to their expressions of Cognition and Motivation levels derived from scores on the attributes, Focus on planning and Deliberation, and, Self-motivation and Winning instinct, respectively in each case. Although the male participants scored higher for both Cognition and Motivation parameters, the vast majority of attributes predicting or counter-predicting Cognition and Motivation, respectively, were similar among the male and female participants, i.e., gender did not separate these attributes. Self-motivation, self-control and focus on detail were predictive for cognition among women whereas mood stability and will-power were expressed among men; openness was counter-predictive for women and communicability for men. Among women, resilience and risk-taking were predictive for motivation whereas focus on details, development motivation and need for speed were expressed by men; openness was counter-predictive for women. Amongst the most predictive attributes for cognition, tolerant attitude was counterpredictive for women whereas risk-taking was expressed for men; for motivation, openness was counter-predictive for women whereas communicability was expressed for men. The findings are discussed from social cognitive organizational trends that permeate current notions of what may constitute an effective leadership "toolbox".
\end{abstract}

Keywords: Leadership inventory; Recruitment; Cognition; Motivation

\section{Introduction}

Personal attributes affect and are affected by expectations associated with performance levels emerging from positive or negative consequences of information received by individuals in leadership positions or under fostering for leadership positions [1,2] among considerations of personal attributes for leadership positions, gender and distinctive ethnicity exert influences comparable to psychological trait [3]. Despite female medical graduates comprising more than $40 \%$ of those successful, the composition of directorships of medical board presents a markedly lower percentage of women [4], with similar trends among other academic medical associations [5], in spite of attempts to understand gender-related attitudes [6]. Nevertheless, both public and corporate administrations require the benefits of attribute-multiplicity that female leadership may endower [7], which implies that obstacles hindering female leadership recruitment as well as those reducing motivation to apply need to be addressed [8-10]. Despite efforts to the contrary, there persists leadership situations in which women in leading positions, albeit underrepresented, report that they have been disadvantaged as a result of their gender [11]. It seems hardly a secret that there still remains some degree of inertia, for a multitude of reasons; among female applicants seeking or assuming executive leadership positions since various barriers for eventual recruitment appear to be a hindrance, such as real or apparent discriminatory tendencies, parenthood or lack of interest in leadership [12-15].

Individual leader recruitment remains dependent upon a plethora of instruments, invariably utilizing personality and personal profiles, for the assessment of attributes/traits to identify decision-making, coping skills, stress-tolerance, communicative skills and numerous qualities that may contribute to effective executive performance within those concerns [16]. Originally, the Job Match Talent (JMT) recruitment test instrument was developed by Olsen [17], in collaboration with recruitment consultants, to provide a suitably designed and adapted tool for selecting competent and experienced individuals for the particular positions sought by corporate and governmental agencies for the purposes of assuming a variety of leadership appointments. To this end, the Job Match Talent test estimates individuals' attributes that are associated with occupational leadership roles in relation to type of enterprise, level of leadership and the age-at-recruitment of applicants. In a large exploratory report, consisting of a data-base derived from over 6700 recruitment participants seeking leadership positions, the psychometric measurement of personality-related attributes of individuals who had applied for executive positions displayed marked and consistent relationships between the participants' age-group and their self-reported personal profiles [17]. It was shown that at the higher age levels the candidates for executive leadership positions expressed a lesser interest and focus upon the specific aspects of the tasks associated with 'job-performance' and lesser orientation towards their own personal ambitions and goals; they expressed rather greater concern for the development of their staff and teams and shaping relationships within the teams within which they functioned.

Gender, levels of education and degree of experience (years) failed to influence significantly those strengths presented in leadership profiles whereas leaders were more likely to express "achiever-strength" than non-leaders. Consequently, it comes as no surprise that it is both organizational and personal factors that emerge as gender-related challenges against women attempting to procure leader status [9]. As indicated previously [18], organizational obstacles have been shown to

*Corresponding author: Trevor Archer, Department of Psychology, University of Gothenburg, Gothenburg, Sweden, Tel: +46 3178642 72; E-mail: trevor.archer@ psy.gu.se

Received: December 26, 2016; Accepted: January 02, 2017; Published: February 09, 2017

Citation: Archer T, Arntén AC, Olsen K, Jansson B (2016) Self-reported Attributes Associated with Cognition and Motivation as a Function of Gender. Clin Exp Psychol 2: 146. doi: 10.4172/2471-2701.1000146

Copyright: ( 2016 Archer T, et al. This is an open-access article distributed under the terms of the Creative Commons Attribution License, which permits unrestricted use, distribution, and reproduction in any medium, provided the original author and source are credited. 
occur through gender-stereotyping and preexisting "good-old-boys" networks whereas personal influences included a paucity of leadership aspirations (see above), often arising from an insufficiency of role models, family and parenthood and a surfeit of workplace mentors. A 'transformational leadership' with greater interpersonal-orientation was more likely to be endorsed be female applicants to executive posts [19-21]. Thus, in an industrial setting, female-dominated industries exhibited greater interpersonal-orientation than the male-dominated industries, with the former reporting more pressure from their positions [22]. The influence of gender upon leadership styles, as well as stress and mental health, seems essential to understanding leadership efficacy not least with regard to workplace resilience [23]. In this regard, the question arises as to whether or not leadership development initiatives promote leadership strengths for both genders or whether leadership strengths vary with position/culture in the context of: (i) equal access to resources and opportunities, (ii) minimizing unconscious gender bias, (iii) enhancing work-life balance, and (iv) promoting leadership engagement [24]. In view of the paucity of women in senior veterinary positions, Castro and Armitage-Chan [25] examined the influences of gender, self-esteem and year-of-study upon these tendencies. They observed that career aspiration and leadership ambition were modulated by gender with greater numbers of males students than female students presenting career aspirations which were influenced positively by selfesteem, self-confidence and experience of previous leadership in clubs/ societies all of which more apparent in the male students.

The purpose of the present study was (i) to determine whether or not the self-reported personal attributes of male and female applicants were at variance with each other, and (ii) to explore whether or not there was any difference in which attributes were predictive of "cognition" and "motivation" by male and female applicants for executive leadership positions. Expressed differences arising from self-reported attributes from male and female applicants do not necessarily reflect a greater or lesser degree of suitability/appropriateness for leadership roles since effectiveness is determined by a multitude of encroaching situational and cultural pressures. Thus, attributes predicting "cognition" and "motivation" by male and female applicants, respectively, may uncover ingredients of the leadership 'tool-box' as a property of gender.

\section{Materials and Methods}

\section{Participants}

A general grouping of executive leaders $(\mathrm{N}=6789)$ participated. The mean age of the leaders was 44 years $(S D=9.3)$. There were $39 \%$ women and $61 \%$ men included in the study.

\section{Instrument}

Personal attitudes to and experiences of job relations and characteristics were measured with the occupational recruitment Job Match Talent (JMT) inventory. The JMT test is based on ten main scales, each presenting three subscales, and has been shown to possess a high level of congruence with health- and personality-related instruments [26]. For a detailed description of the scales, see [17].

\section{Statistical procedure}

Initially, analyses were done by use of analysis of variance (ANOVA) and co-variance (ANCOVA). Dependent variables were 'Cognition' (index for a1: Focus on planning and d1: Deliberation) and 'Motivation' (index for b1: Self-motivation abd f1: Winning instinct), respectively. Independent variable was gender, and age of leaders was used as a covariate. Conditions of the ANCOVAs were controlled for (independence between main effect and covariate; parallel slopes of lines). Moreover, the indices Cognition and Motivation were regressed on the JMT subscales over gender, respectively.

\section{Results}

It was shown that male participants expressed higher levels of both Cognition $(\mathrm{F}(1,6787)=30.2, \quad \mathrm{p}<0.001)$. and Motivation $(F(1,6787)=205.0, p<0.001)$, as defined by scoring to the attributes, planning and deliberation, and self-motivation and winning instinct, respectively, than the female participants The effects of gender were still significant $(\mathrm{F}(1,6786)=30.5, \mathrm{p}<0.001$ for Cognition; $\mathrm{F}(1,6786)=217.3$, $\mathrm{p}<0.001$ for Motivation) if the co-variate age of leaders $(\mathrm{p}<0.001)$ was included in ANCOVAs. The conditions for the ANCOVAs were fulfilled (Figure 1).

\section{Cognition}

Focus on planning and deliberation attributes; motivation; selfmotivation and winning instinct attributes.

\section{Regression analysis}

Regression analysis with Cognition as the dependent variable: $F(17$, $2640)=122.9, \mathrm{p}<0.0001$, adj. $\mathrm{R}^{2}=0.438$, and revealed that the following attributes were predictive in the following orders of significance: For female participants: Focus on order, Diplomacy, Sphere of influence, Vision, Self-motivation, Development motivation, Persistence, Physical activity, Self-control and Focus on detail whereas the following attributes were counter-predictive: Need for speed, Power of initiative, Optimism, Risk-taking, Tolerant attitude, Displayed consideration and Openness; For the male participants, $\mathrm{F}(19,4111)=190.3$, $\mathrm{p}<0.0001$, adj. $\mathrm{R}^{2}=0.466$, the following were predictive: Focus on order, Diplomacy, Sphere of influence, Vision, Will-power, Development motivation, Persistence, Physical activity, and Mood stability whereas the following attributes were counter-predictive: Need for speed, Power of initiative, Optimism, Risk-taking, Tolerant attitude, and communicability. Note, the bold style text indicates those attributes that differed between

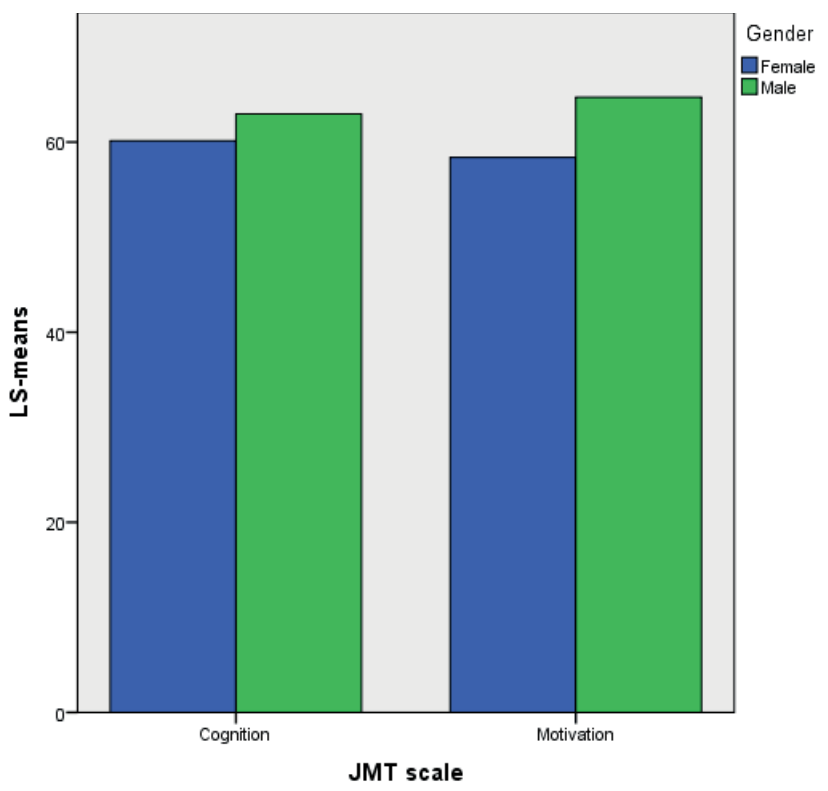

Figure 1: Least-squares means (LS-means) for cognition and motivation as expressed by male and female applicants for leadership positions $(\mathrm{N}=6789$; Males=4141, Females=2648) 
Citation: Archer T, Arntén AC, Olsen K, Jansson B (2016) Self-reported Attributes Associated with Cognition and Motivation as a Function of Gender. Clin Exp Psychol 3: 146. doi: 10.4172/2471-2701.1000146

Page 3 of 6

male and female participants. The pattern emerging from this analysis indicates that most of the predictive attribute were shared by female and male participants. However, self-motivation, Self-control and Focus on detail were predictive for the former but not the latter, and Will power and Mood stability were predictive for the latter but not the former. Counter-predictive attributes indicated that Openness was counterpredictive for women and Communicability for men (Table 1).

Regression analysis with motivation as the dependent variable: $\mathrm{F}(19,2638)=234.1, \mathrm{p}<0.0001$, adj. $\mathrm{R}^{2}=0.625$, revealed that the following attributes were predictive for both female and male participants:
Vision, Power of initiative, Will-power, Mental energy, Impact, Physical activity, Persistence, Focus on order, Mood stability, Sphere of influence, Focus on planning, Concurring image, and concentration whereas the following were shared counter-predictive attributes: Optimism, Communicability and Trust in others. The following attributes were predictive for women's Motivation only: Resilience and Risk-taking whereas for men, $F(20,4110)=335.6, p<0.0001$, adj. $R^{2}=0.618$, it was Focus on detail, Development motivation and Need for speed. Openness was counter-predictive for motivation among women.

Analysis of the five highest Beta values for male and female

\begin{tabular}{|c|c|c|c|c|c|c|c|c|c|}
\hline \multicolumn{5}{|c|}{ Female participants } & \multicolumn{5}{|c|}{ Male participants } \\
\hline Scale & B & SE & Beta & p & Scale & B & SE & Beta & p \\
\hline Need for speed & -0.284 & 0.028 & -0.269 & 0 & Need for speed & -0.297 & 0.02 & -0.281 & 0 \\
\hline Focus on order & 0.156 & 0.014 & 0.19 & 0 & Focus on order & 0.183 & 0.011 & 0.221 & 0 \\
\hline Power of initiative & -0.17 & 0.021 & -0.175 & 0 & Optimism & -0.17 & 0.015 & -0.207 & 0 \\
\hline Optimism & -0.142 & 0.018 & -0.171 & 0 & Risk-taking & -0.197 & 0.015 & -0.202 & 0 \\
\hline Tolerant attitude & -0.134 & 0.02 & -0.126 & 0 & Power of initiative & -0.148 & 0.017 & -0.152 & 0 \\
\hline Risk taking & -0.127 & 0.019 & -0.124 & 0 & Vision & 0.141 & 0.02 & 0.137 & 0 \\
\hline Diplomacy & 0.113 & 0.019 & 0.112 & 0 & Tolerant attitude & -0.111 & 0.015 & -0.107 & 0 \\
\hline Sphere of influence & 0.121 & 0.02 & 0.111 & 0 & Sphere of influence & 0.1 & 0.015 & 0.102 & 0 \\
\hline Vision & 0.115 & 0.024 & 0.109 & 0 & Development motivation & 0.143 & 0.02 & 0.086 & 0 \\
\hline Displayed consideration & -0.1 & 0.016 & -0.104 & 0 & Displayed consideration & -0.079 & 0.013 & -0.085 & 0 \\
\hline Self-motivation & 0.123 & 0.026 & 0.1 & 0 & Physical activity & 0.127 & 0.021 & 0.08 & 0 \\
\hline Development motivation & 0.121 & 0.027 & 0.068 & 0 & Persistence & 0.068 & 0.012 & 0.068 & 0 \\
\hline Persistence & 0.058 & 0.017 & 0.057 & 0.001 & Willpower & 0.065 & 0.02 & 0.063 & 0.001 \\
\hline Physical activity & 0.084 & 0.026 & 0.054 & 0.001 & Diplomacy & 0.062 & 0.015 & 0.062 & 0 \\
\hline Self-control & 0.046 & 0.02 & 0.053 & 0.019 & Mood stability & 0.057 & 0.013 & 0.061 & 0 \\
\hline Openness & -0.048 & 0.017 & -0.047 & 0.006 & Winning instinct & 0.055 & 0.018 & 0.055 & 0.003 \\
\hline \multirow[t]{2}{*}{ Focus on details } & 0.03 & 0.015 & 0.036 & 0.042 & Openness & -0.051 & 0.015 & -0.053 & 0.001 \\
\hline & & & & & Communicativity & -0.038 & 0.017 & -0.041 & 0.024 \\
\hline
\end{tabular}

Table 1a: Cognition.

\begin{tabular}{|c|c|c|c|c|c|c|c|c|c|}
\hline \multicolumn{5}{|c|}{ Female participants } & \multicolumn{5}{|c|}{ Male participants } \\
\hline Scale & B & SE & Beta & p & Scale & B & SE & Beta & p \\
\hline Vision & 0.347 & 0.016 & 0.378 & 0 & Vision & 0.29 & 0.013 & 0.331 & 0 \\
\hline Power of initiative & 0.194 & 0.015 & 0.23 & 0 & Power of initiative & 0.207 & 0.013 & 0.249 & 0 \\
\hline Willpower & 0.192 & 0.017 & 0.21 & 0 & Willpower & 0.21 & 0.013 & 0.239 & 0 \\
\hline Mental energy & 0.248 & 0.025 & 0.182 & 0 & Communicativity & -0.137 & 0.012 & -0.176 & 0 \\
\hline Optimism & -0.126 & 0.012 & -0.175 & 0 & Mental energy & 0.16 & 0.021 & 0.124 & 0 \\
\hline Communicativity & -0.103 & 0.015 & -0.132 & 0 & Physical activity & 0.149 & 0.015 & 0.111 & 0 \\
\hline Impact & 0.097 & 0.02 & 0.107 & 0 & Optimism & -0.077 & 0.01 & -0.111 & 0 \\
\hline Physical activity & 0.142 & 0.017 & 0.106 & 0 & Mood stability & 0.088 & 0.01 & 0.11 & 0 \\
\hline Persistence & 0.081 & 0.012 & 0.091 & 0 & Persistence & 0.089 & 0.009 & 0.105 & 0 \\
\hline Focus on order & 0.056 & 0.01 & 0.079 & 0 & Impact & 0.074 & 0.016 & 0.087 & 0 \\
\hline Mood stability & 0.058 & 0.013 & 0.076 & 0 & Focus on order & 0.05 & 0.008 & 0.072 & 0 \\
\hline Trust in others & -0.052 & 0.012 & -0.059 & 0 & Trust in others & -0.054 & 0.009 & -0.066 & 0 \\
\hline Sphere of influence & 0.052 & 0.014 & 0.056 & 0 & Need for speed & 0.055 & 0.015 & 0.061 & 0 \\
\hline Focus on planning & 0.043 & 0.012 & 0.051 & 0 & Displayed consideration & -0.038 & 0.011 & -0.048 & 0.001 \\
\hline Openness & -0.043 & 0.013 & -0.049 & 0.001 & Focus on planning & 0.034 & 0.01 & 0.042 & 0.001 \\
\hline Concurring image & 0.04 & 0.013 & 0.044 & 0.003 & Concurring image & 0.034 & 0.014 & 0.038 & 0.02 \\
\hline Resilience & 0.035 & 0.014 & 0.041 & 0.011 & Concentration & 0.032 & 0.01 & 0.035 & 0.001 \\
\hline Risk taking & 0.035 & 0.014 & 0.039 & 0.015 & Focus on details & 0.021 & 0.008 & 0.031 & 0.012 \\
\hline \multirow[t]{2}{*}{ Concentration } & 0.031 & 0.012 & 0.034 & 0.007 & Sphere of influence & 0.026 & 0.01 & 0.031 & 0.013 \\
\hline & & & & & Development motivation & 0.032 & 0.014 & 0.022 & 0.028 \\
\hline
\end{tabular}

Table 1b: Motivation

Table 1: Stepwise regression coefficients over gender, male and female participants, for the dependent variables, cognition (1a) and motivation (1b), respectively, on the JMT subscales; coefficients are sorted by beta-values as well as $\mathrm{B}, \mathrm{SE}$ and $\mathrm{p}$-values, respectively ( $\mathrm{N}=6789$ ). The predictor variables, for cognition (1a), need for speed, focus on order, etc., and motivation (1b) vision, power of initiative, etc., are listed below with beta values and significance level. 
participants gave differing patterns over gender for Cognition and Motivation, as follows:

Cognition: Tolerant attitude was counter-predictive for females but Risk-taking for males.

Motivation: Optimism was counter-predictive for females but Communicability for males (Table 2).

\section{Discussion}

The present findings pertain to the apparent or real differences in self-reported leadership gender attributes in relation to characteristics associated with (a) cognition and (b) motivation, between male and female applicants for executive appointments. The results may be summarized as follows: (i) The direct comparison of male and female participants indicated that the male participants reported higher levels of both cognition and motivation (Figure 1). Does this result imply that the males expressed greater cognitive capacity and a higher level of motivation than the females? In order to examine the veracity of this comparison regression analyses were performed to ascertain which attributes were associated with cognition and motivation among male and female participants respectively. (ii) The vast majority of attributes predicting or counter-predicting Cognition and Motivation, respectively, were similar among the male and female participants, i.e., gender did not separate these attributes (Table 1). (iii) Self-motivation, self-control and focus on detail were predictive for cognition among women whereas mood stability and will-power were expressed among men; openness was counter-predictive for women and communicability for men. (iv) Among women, resilience and risk-taking were predictive for motivation whereas focus on details, development motivation and need for speed were expressed by men; openness was counterpredictive for women. (v) Amongst the most predictive attributes for cognition, tolerant attitude was counter-predictive for women whereas risk-taking was expressed for men; for motivation, openness was counter-predictive for women whereas communicability was expressed for men. These patterns of predictability for Cognition and Motivation, respectively, would seem to imply that the female and male recruitment participants were each possessed of "leadership toolboxes" which we have termed "Cognition" and "Motivation".

The present results suggest that the tentative 'label' "tools" or attributes/ingredients provided in each "toolbox", i.e., whether Cognition "toolbox" or a Motivation "toolbox", remain essentially the same, with the exceptions noted above. The finding that the Cognition and Motivation "toolboxes" for women was 'smaller' than that of the men does not imply a higher leadership prowess by the latter but rather that each possess slightly differing 'tools' for employment since it is the application of those leadership tools that remains the major issue. It was shown previously that "Willingness-to-take-risks" was observed to be the single attribute upon which female and male applicants differ with the latter expressing a greater extent [18]. None of the

\begin{tabular}{|c|c|c|c|}
\hline Scale & SE & Beta & p \\
\hline Females & & -0.269 & $<0.0001$ \\
\hline E3: Need for speed & 0.028 & 0.190 & $<0.0001$ \\
\hline A3: Focus on order & 0.014 & -0.175 & $<0.0001$ \\
\hline G2: Power of initiative & 0.021 & -0.171 & $<0.0001$ \\
\hline B2: Optimism & 0.018 & -0.126 & $<0.0001$ \\
\hline H2: Tolerant attitude & 0.020 & & $<0.0001$ \\
\hline Males & & -0.281 & $<0.0001$ \\
\hline E3: Need for speed & 0.020 & 0.221 & $<0.0001$ \\
\hline A3: Focus on order & 0.011 & -0.207 & $<0.0001$ \\
\hline B2: Optimism & 0.015 & -0.202 & $<0.0001$ \\
\hline G3: Risk-taking & 0.015 & -0.152 & $<$ \\
\hline$z$ & 0.017 & & $<$ \\
\hline
\end{tabular}

Table 2a: Beta values and significance levels for attributes predicting cognition.

\begin{tabular}{|c|c|c|}
\hline Scale & SE & Beta \\
\hline Females & & 0.016 \\
\hline F2: Vision & 0.015 & 0.378 \\
\hline G2: Power of initiative & 0.017 & 0.230 \\
\hline D2: Willpower & 0.025 & 0.210 \\
\hline E2: Mental energy & 0.012 & 0.182 \\
\hline B2: Optimism & & -0.175 \\
\hline Males & & \\
\hline F2. Vision & 0.016 & \\
\hline G2: Power of initiative & 0.015 & \\
\hline D2: Willpower & 0.017 & 0.331 \\
\hline J2: Communicability & 0.025 & 0.249 \\
\hline E2: Mental energy & 0.012 & 0.239 \\
\hline
\end{tabular}

Table 2b: Beta values and significance levels for attributes predicting motivation.

Table 2: Stepwise regression coefficients over gender for cognition (Table 2a) and Motivation (Table 2b), respectively, as the dependent variables and the five most predictive attributes on the JMT subscales in each case as the predictor variables; coefficients are sorted by beta-values ( $\mathrm{N}=6789$ ). 
Citation: Archer T, Arntén AC, Olsen K, Jansson B (2016) Self-reported Attributes Associated with Cognition and Motivation as a Function of Gender. Clin Exp Psychol 3: 146. doi: 10.4172/2471-2701.1000146

other attributes studied, including "humor-equilibrium", "resilience", "will-power", "stamina", "initiative", "assent-image" and "openness" differed between the genders. Taking into account previous, traditional notions regarding the differential capacity of male and female leaders to withstand 'stress-and-strain', those findings demonstrated that the concomitant examination participants' variations due to age effects imply that leadership-strength attributes are modulated by age rather than gender per se. The effect of gender on cognition and motivation was controlled for by use of the covariate age of leaders. Although age had a significant effect for both cognition and motivation, the impact of gender was not influenced. This result was different compared to the reduced gender effects that were found for eight JMT scales in a previous study [18].

The organizational context in social cognition underlying leadership perceptions has not received much attention despite the plethora in institutional reports that touch upon associated issues [27,28]. Özalp et al. [29] examined a range of subordinates' perceptions of individuals in managerial positions as leaders (i.e., to the extent they may or may not perceive their managers as a leaders) as a potential mediating factor to explain the relationship between managers' self-monitoring and their subordinates' attitudes toward their organizations among middlelevel managers and their subordinates taken from different business organizations in Turkey. They observed that subordinates 'leadership perceptions of their managers mediated the relationship between managers' self-monitoring and their subordinates' affective and normative organizational commitments implying that the managerial "toolbox" is required to present both variance and adaptability to context. In this regard, the importance of developmentally sequencing leadership-learning experiences and addressing evolving complexities of leadership identity reinforces the observed necessity of a wide of attributes to buttress leadership style [30], in the present case involving the cognition and motivation leadership "toolboxes". Finally, there is an ever-increasing consensus for the requirement of a leadership of sensemaking, through the fermenting of, for example the "toolbox" type of notion, that implements front-line staff managers to exercise their collective discretionary power in strengthening [31].

\section{Limitations}

In order to extract a deeper understanding of the real or apparent nature of posited gender influences, it is suggested, from the influence of resilience and risk-taking which were predictive for women's motivation, that coming investigations ought to be devoted to the recruitment utility propensity of the JMT instrument through coadministration with the Workplace Resilience Instrument which optimizes factors involving "active problem-solving", "team efficacy", confident "sense-making" and "bricolage" [23].

\section{References}

1. Guise JM, Geller S, Regensteiner JG, Raymond N, Nagel J, Building Interdisciplinary Research Careers in Women's Health Program Leadership (2016) Team mentoring for interdisciplinary team science: lessons from K12 scholars and directors. Acad Med 2016.

2. Motro D, Ellis AP (2016) Boys don't cry: gender and reactions to negative performance feedback. J Appl Psychol.

3. Lake DM, Allen PE, Armstrong ML (2016) Capitalizing on military nurse skills for second-career leadership and staff development roles. J Contin Educ Nurs 47: $503-510$

4. Walker LE, Sadosty AT, Coletti JE, Goyal DG, Sunga KL, et al. (2016) Gender distribution among American Board of Medical Specialities Boards of Directors. Mayo Clin Proc 91: 1590-1593.

5. Abelson JS, Chartrand G, Moo TA, Moore M, Yeo H (2016) The climb to break the glass ceiling in surgery: trends in women progressing from medical schoo to surgical training and academic leadership from 1994 to 2015 . Am J Surg 212: 566-572.

6. Kanamori Y, Cornelius-White JH, Pegors TK, Daniel T, Hulgus J (2016) Development and validation of the transgender attitudes and beliefs scale. Arch Sex Behav.

7. Silva AK, Preminger A, Slezak S, Phillips LG, Johnson DJ (2016) Melting the plastic ceiling: overcoming obstacles to foster leadership in women plastic surgeons. Plast Reconstr Surg 138: 721-729.

8. Brosi P, Spörrle M, Welpe IM, Heilman ME (2016) Expressing pride: Effects on perceived agency, communality, and stereotype-based gender disparities. J Appl Psychol 101: 1319-1328.

9. Mazerolle SM, Eason CM (2016a) Barriers to the role of head athletic traine for women in national collegiate athletic association division II and III settings. J Athl Train 51: 557-65.

10. Mazerolle SM, Eason CM (2016b) Positive factors influencing the advancement of women to the role of head athletic trainer in the National Collegiate Athletic Divisions II and III. J Ath Train 51: 550-556.

11. Hawker FH (2016) Female specialists in intensive care medicine: Job satisfaction, challenges and work-life balance. Crit Care Resusc 18: 125-131.

12. Appelbaum SH, Audet S, Miller JC (2003) Gender and leadership? A journey through the landscape of theories. Leadership Organiz Devel J 24: 43-51.

13. Ayman R, Korabil K (2010) Leadership: Why gender and culture matter. Amer Psychol 65: 157-170.

14. Eagly AH (2005) Achieving relational authenticity in leadership: Does gender matter? The Leadership Quart 16: 459-474.

15. Vecchio RP (2002) Leadership and gender advantage. The Leadership Quart 13: $643-671$.

16. Roberts-Turner R, Hinds PS, Nelson J, Pryor J Robinson NC, et al. (2014) Effects of leadership characteristics on pediatric registered nurses' job satisfaction. Pediatr Nurs 40: 236-241.

17. Archer T, Jansson B, Olsen K (2015) Effect of age upon leadership attributes from recruitment instrument: a selective developmental trajectory. Clin Exp Psychol 1: 1-4.

18. Archer T, Arntén AC, Olsen K, Jansson B (2016) Age and gender influence upon self-reported leadership attributes during recruitment. Clin Exp Psychol 2:1-3.

19. Burke S, Collins KM (2001) Gender differences in leadership styles and management skills. Women Managem Rev 16: 244-257.

20. Carless SA (1998) Gender differences in transformational leadership: An examination of superior, leader, and subordinate perspectives. Sex Roles 39 : 887-902.

21. Trinidad C, Normore AH (2005) Leadership and gender: A dangerous liaison? Leadership Organiz Devel J 26: 574-590.

22. Gardiner M, Tiggemann M (1999) Gender differences in leadership style job stress and mental health in male - and female - dominated industries. J Occupation Organization Psychol 72: 301-315.

23. Mallak LA, Yildiz M (2016) Developing a workplace resilience instrument. Work 54: 241-253.

24. Westring A, McDonald JM, Carr P, Grisso JA (2016) An integrated framework for gender equity in academic medicine. Acad Med 91: 1041-1044.

25. Castro SM, Armitage CE (2016) Career aspiration in UK veterinary students: the influences of gender, self-esteem and year of study. Vet Rec.

26. matchtalent test and the NEO PI-R: Construct. Validation of an instrument designed for recruitment of personnel. PLoS ONE 9: Garcia D, Nima AA Rappe C, Rapp Ricciardi M, Archer T (2014) The relationship between the job e90309.,

27. Balkundi P, Kilduff M, Harrison DA (2011) Centrality and charisma: Comparing how leader networks and attributions affect team performance. J Appl Psychol 96: 1202-1222.

28. Lord RG, Gatti P, Chui SLM (2016) Social cognitive relational, and identitybased approaches to leadership. Organisa Beh Hum Dec Proc 136: 119-134.

29. Özalp Türetgen I, Unsal P, Dural U (2016) The role of leadership perception 
Citation: Archer T, Arntén AC, Olsen K, Jansson B (2016) Self-reported Attributes Associated with Cognition and Motivation as a Function of Gender. Clin Exp Psychol 3: 146. doi: 10.4172/2471-2701.1000146

Page 6 of 6

as a mediator between managers' self-monitoring and subordinate attitudes. $\mathrm{J}$ Soc Psychol 23: 1-13.

30. Torrez MA, Rocco ML (2015) Building critical capacities for leadership learning. New Dir Stud Leadersh 145: 19-34.
31. Gilson L, Elloker S, Olckers P, Lehmann U (2014) Advancing the application of systems thinking in health: South African examples of a leadership of sensemaking for primary health care. Health Res Policy Syst 12: 30 